\title{
Non-Invasive Detection and Staging of Colorectal Cancer Using a Portable Electronic Nose
}

\author{
Heena Tyagi ${ }^{1}$, Emma Daulton ${ }^{1}$, Ayman S. Bannaga ${ }^{2,3} \mathbb{D}$, Ramesh P. Arasaradnam $2,3,4,5$ (D) \\ and James A. Covington 1,*(D) \\ 1 School of Engineering, University of Warwick, Coventry CV4 7AL, UK; Heena.tyagi@warwick.ac.uk (H.T.); \\ e.daulton@warwick.ac.uk (E.D.) \\ 2 Department of Gastroenterology, University Hospital Coventry \& Warwickshire, Coventry CV2 2DX, UK; \\ ayman.bannaga@warwick.ac.uk (A.S.B.); r.arasaradnam@warwick.ac.uk (R.P.A.) \\ 3 Warwick Medical School, University of Warwick, Coventry CV4 7AL, UK \\ 4 School of Health Sciences, Coventry University, Coventry CV1 5FB, UK \\ 5 Leicester Cancer Centre, University of Leicester, Leicester LE1 7RH, UK \\ * Correspondence: j.a.covington@warwick.ac.uk
}

check for updates

Citation: Tyagi, H.; Daulton, E.; Bannaga, A.S.; Arasaradnam, R.P.; Covington, J.A. Non-Invasive Detection and Staging of Colorectal Cancer Using a Portable Electronic Nose. Sensors 2021, 21, 5440. https:// doi.org/10.3390/s21165440

Academic Editor: Arnaud Buhot

Received: 5 July 2021

Accepted: 30 July 2021

Published: 12 August 2021

Publisher's Note: MDPI stays neutral with regard to jurisdictional claims in published maps and institutional affiliations.

Copyright: (c) 2021 by the authors. Licensee MDPI, Basel, Switzerland. This article is an open access article distributed under the terms and conditions of the Creative Commons Attribution (CC BY) license (https:/ / creativecommons.org/licenses/by/ $4.0 /)$.

\begin{abstract}
Electronic noses (e-nose) offer potential for the detection of cancer in its early stages. The ability to analyse samples in real time, at a low cost, applying easy-to-use and portable equipment, gives e-noses advantages over other technologies, such as Gas Chromatography-Mass Spectrometry (GC-MS). For diseases such as cancer with a high mortality, a technology that can provide fast results for use in routine clinical applications is important. Colorectal cancer (CRC) is among the highest occurring cancers and has high mortality rates, if diagnosed late. In our study, we investigated the use of portable electronic nose (PEN3), with further analysis using GC-TOF-MS, for the analysis of gases and volatile organic compounds (VOCs) to profile the urinary metabolome of colorectal cancer. We also compared the different cancer stages with non-cancers using the PEN3 and GC-TOF-MS. Results obtained from PEN3, and GC-TOF-MS demonstrated high accuracy for the separation of CRC and non-cancer. PEN3 separated CRC from non-cancerous group with 0.81 AUC (Area Under the Curve). We used data from GC-TOF-MS to obtain a VOC profile for CRC, which identified 23 potential biomarker VOCs for CRC. Thus, the PEN3 and GC-TOF-MS were found to successfully separate the cancer group from the non-cancer group.
\end{abstract}

Keywords: electronic nose; colorectal cancer; PEN3; GC-TOF-MS; VOCs

\section{Introduction}

Cancer remains a leading cause of death worldwide, with approximately 19.3 million new cases and 10 million deaths in 2020 [1]. Survival rates depend on early detection; however, many current methods do not provide the means to achieve this or are not applied [2]. One potential method to support cancer detection is through the measurement of Volatile Organic Compounds (VOCs) that reflect the biological process of disease. These bodily VOCs are the reflection of the physiological effects and metabolism of the individual and the environment surrounding them. They are generated as the products of the biological activities inside the body and can be released from saliva, urine, breath, blood, or faeces [3-6]. Cancer causes changes in these biological pathways leading to the emission or omission of specific VOCs [7].

Colorectal cancer (CRC) is the second leading cause of the cancer-related deaths and third leading cause of cancer-related deaths among men and women, respectively, in Europe [8]. As such, screening using faecal immunochemical testing for haemoglobin (FIT) has been introduced but still can miss up to $10 \%$ of cancers [9-11]. More recently, there is evidence to suggest addition of VOC to FIT can further improve diagnosis of CRC [12]. Colonoscopy is considered the most reliable way of detecting CRC at both early 
and advanced stages, but the rate of detection depends upon the operator performing the procedure. Furthermore, colonoscopy is an invasive, expensive, and uncomfortable procedure with a small risk of bowel injury $[13,14]$.

Several techniques are available for the detection and analysis of VOCs. Gas Chromatography-Mass Spectrometry (GC-MS) is considered as the gold standard method for the detection of VOCs with high sensitivity and specificity. However, these analytical methods may be unsuitable for practical implementation as they are expensive, have long analysis times, and require highly trained personnel. An alternative is the electronic nose (e-nose), which can be used as a non-invasive, rapid, portable piece of equipment that may also provide results at a lower cost per test. An e-nose is an instrument that is designed to sense odours, rather than individually, and typically differentiates them using an array of diverse chemical sensors. There is a wide range of different sensing technologies that can be used inside an e-nose, including surface acoustic wave (SAW) $[15,16]$ quartz crystal microbalance (QCM) [17,18], metal oxide semiconductors (MOS) [19-21], conducting polymers (CP) [22], and carbon nanofiber (CNF) [23]. However, MOS-based electronic noses are by far the most common. E-nose technology has previously been used in diverse areas, such as environmental [24,25], food [26,27], pharmaceutical [28,29], biomedical applications [20,30-32], and many other fields of applied science.

Many diseases have their own chemical fingerprint, which can be detected by an electronic nose. If we know the chemical fingerprint of a disease, it could be potentially used as a means to identify undiagnosed patients [33-35]. Several studies have demonstrated that the e-nose has the ability to detect, differentiate, and identify different cancers. A study was conducted by Di Natale et al. to differentiate between 42 lung cancer patients and 18 healthy controls using breath samples using e-nose based on quartz microbalance (QMB). They were able to identify $100 \%$ lung cancer patients and $94 \%$ healthy controls [36]. Another study conducted by Westenbrink et al. using a custom e-nose consisting of 13 sensors. They were able to successfully distinguish CRC from Irritable Bowel Syndrome (IBS) using urine samples with a sensitivity of $78 \%$ and specificity of $79 \%$ [37]. Several other studies have been conducted evaluate the potential of e-nose to differentiate and detect lung cancer [15,38-41], breast cancer [42], CRC [43,44] and prostate cancer [45,46].

The present study aimed to evaluate the use of PEN3 (Portable Electronic Nose) as a potential e-nose for detection and discrimination between cancer groups and healthy controls. Simultaneously, Gas Chromatography-Time of Flight-Mass Spectrometry (GCTOF-MS) was used to differentiate cancer group (CRC) from healthy controls and different cancer stages from healthy controls and to determine urinary odour volatile chemicalprint for CRC by using the volatile chemical print obtained from urine samples. Urine is commonly used for detection as it is non-invasive and easily obtained from patients. To our knowledge, this is the first study undertaken using the PEN3 applied to the testing of CRC urine samples.

\section{Materials and Methods}

\subsection{Urine Samples}

This study includes the analysis of 96 urine samples acquired at University Hospital Coventry and Warwickshire NHS Trust, after patients provided written informed consent. Out of the 96 samples, there were 58 CRC urine samples and 38 non-cancerous samples. A total of 58 CRC samples were further distributed into 24 early-stage CRC sample and 34 late-stage CRC samples based on TNM (tumour/node/metastasis) staging. We assigned $\mathrm{T} 1$ and T2 stage as early-stage and T3 and T4 as late-stage samples. The samples were contained in standard universal sterile specimen containers and frozen within $2 \mathrm{~h}$ at $-80^{\circ} \mathrm{C}$. This was to allow batch testing of all the samples once they had been collected. The study was approved by Coventry and Warwickshire and North-East Yorkshire NHS Ethics Committees (Ref 18717 and Ref 260179). The samples were later analysed at the University of Warwick. The samples were shipped to the University on dry ice and then stored at $-20^{\circ} \mathrm{C}$ until analysed, which was within a few days of arrival. For analysis, the 
samples were defrosted and transferred into $20 \mathrm{~mL}$ glass vials with crimp caps. A total of $5 \mathrm{~mL}$ of each urine sample was used for the analysis using PEN3 and GC-TOF-MS. The demographic information of the subjects recruited into this study are provided in Table 1.

Table 1. Clinical characteristics of the recruited study participants at time of obtaining the urine samples.

\begin{tabular}{ccc}
\hline Group & CRC & Non-Cancerous \\
\hline Number of samples & $58(24$ early stage and 34 late stage $)$ & 38 \\
Mean Age (years) & $74.7(92-46)$ & $63.2(90-32)$ \\
Sex: Male/Female & $40: 18$ & $25: 13$ \\
Avg. BMI & $27.7(34.1-17)$ & $30.5(37.3-22.4)$ \\
Current Smoker & $3(5.2 \%)$ & $3(8.3 \%)$ \\
(Number and \% of patients) & & \\
\hline
\end{tabular}

\subsection{PEN3 Electronic Nose (Airsense Analytics GmbH, Schwerin, Germany)}

PEN3 (Airsense Analytics GmbH, Schwerin, Germany) is a portable $(92 \times 190 \times 255 \mathrm{~mm})$ olfactory system used for the identification of chemicals and gases. It is a combination of a gas sampling unit and a sensor array. In our case the PEN3 is fitted with an autosampler (HT2000H Dynamic Headspace Auto-sampler, Brescia (BS), Italy), which interfaces directly with the PEN 3 software (WinMuster PEN v 1.6.2.18).

The sensor arrays consist of 10 different thick film metal oxide sensors, operating between 250 and $550{ }^{\circ} \mathrm{C}$. Information available about these sensors are included in Table 2 .

Table 2. Description of the sensors used in PEN3 e-nose provided by Airsense Analytical.

\begin{tabular}{ccc}
\hline Sensor No. & Sensors & Substances for Sensing \\
\hline S1 & W1C & Sensitive to aromatic compounds \\
S2 & W5S & Broad range \\
S3 & W3C & Sensitive to aromatic compounds \\
S4 & W6S & Sensitive to hydrogen \\
S5 & W5C & Sensitive to aromatic and aliphatic compounds \\
S6 & W1S & Sensitive to methane in the environment, with broad range \\
S7 & W1W & Sensitive to Sulphur and organic compounds \\
S8 & W2S & Sensitive to alcohol and broad range \\
S9 & W2W & Sensitive to Sulphur compounds \\
S10 & W3S & Sensitive to methane and aliphatic compounds \\
\hline
\end{tabular}

The PEN3 contains two pumps, one is used for pulling the sample gas through the sensor array and the other transfers filtered reference air or zero air into the sensor array. The zero air is also used to clean the system. Zero air is used as a baseline or reference gas, and the sensor response from the sample gas are measured in comparison to the reference gas. Vials containing urine samples were placed in a sample tray of the auto-sampler. These samples were transferred one by one from the sample tray to an internal oven and were heated to increase concentration above the detection limit of the e-nose. Different over and incubation periods were tested, and it was found that with the oven set to $80{ }^{\circ} \mathrm{C}$ and the incubation period set to $8 \mathrm{~min}$ gave the most consistent results. The oven was equipped with an orbital shaker. After heating up the sample, the headspace was sampled by a syringe at a pressure of 5 bar (max.) and a volume of $2.5 \mathrm{~mL}$. The sample was then analysed for $5 \mathrm{~min}$.

\subsection{Markes GC-TOF-MS}

Markes GC-TOF-MS is a combination of TRACE 1300 GC (Thermo Fisher Scientific, Loughborough, UK) and Bench TOF-HD TOF-MS (Markes Intl., Llantrisant, UK). It consists of a high-throughput autosampler and thermal desorption unit, ULTRA-xr and UNITY-xr, respectively (Markes Intl.). The operating principle of GC-TOF-MS is it analyses the Time 
of Flight of ions. The GC component separates chemicals according to their interaction with the stationary phase of the column (liquid) and mobile phase (gas) inside the column. TOF-MS separates fragment ions inside the TOF 'flight box' and detects them according to the mass-to-charge ratio of the ions after passing through the drift tube.

The sample was transferred on to the TD tube (C2-AXXX-5149, Markes Intl., Llantrisant, UK), by heating $5 \mathrm{~mL}$ of urine in a $20 \mathrm{~mL}$ glass vial with a crimp cap. The TD is inserted through the septum and into the headspace of the vial. The urine sample is then heated $40{ }^{\circ} \mathrm{C}$ for $10 \mathrm{~min}$. After $10 \mathrm{~min}$, a pump (Markes Intl.) is attached to the other end of the TD tube and pulls the urine headspace gas onto the TD tube at a rate of $20 \mathrm{~mL} / \mathrm{min}$ for a further $10 \mathrm{~min}$. The samples were then analysed by placing the tubes in the autosampler. The analysis was initiated with ULTRA-xr with a stand-by split set to $150{ }^{\circ} \mathrm{C}$ and GC run time $25 \mathrm{~min}$ with a programmed temperature ramp from $40^{\circ} \mathrm{C}$ to $280{ }^{\circ} \mathrm{C}$ at $20^{\circ} \mathrm{C} / \mathrm{min}$. For each sample, the pre-purge time was $1 \mathrm{~min}$, followed by desorption for $10 \mathrm{~min}$ at $250{ }^{\circ} \mathrm{C}$ and trap purge for $1 \mathrm{~min}$. These traps were then cooled at $-30^{\circ} \mathrm{C}$ followed by purging them for $3 \mathrm{~min}$ at a temperature of $300{ }^{\circ} \mathrm{C}$ [47]. The temperature for both transfer line and ion source was $250^{\circ} \mathrm{C}$. The data obtained was analysed using the national institute of standards and technology (NIST) list (2011).

\subsection{Statistical Analysis}

The data obtained from PEN3 was analysed using MultiSens Analyzer (v2.0.0.22, JLM Innovation $\mathrm{GmbH}$, Germany). MultiSens Analyzer is used to evaluate measurement data from multi sensor instruments, such as electronic noses. MultiSens Analyzer classified the data into different groups and then performed feature extraction. The feature used was the maximum deviation of the signal from the baseline to the response. The resultant data matrix was then analyzed using a 10-fold cross-validation, undertaken using a bespoke $\mathrm{R}$ program (version 3.6.2). In a 10-fold cross-validation the dataset is divided into 10 groups. Keeping one of the groups as a test set, the remaining 9 are used as a training set, to which classification models are created and then applied to the test set. For our study, this was Random Forest (using the "Ranger" function in the 'kernlab' R package') and Neural Network (using the "nnet" package). Random forest consists of many decision trees where each tree produces class prediction and the class with the most prediction is assigned as model's prediction [48]. Neural network classifier consists of layers where first layer is the input, last layer is output, and middle layers are hidden layers. Each layer consists of nodes which converts input into the output [49]. This process was repeated 10 times until all the data had been a test set. These classifiers were chosen as they showed good performance in previous studies [50]. From the resultant probabilities, final statistical results including a Receiver Operator Characteristic (ROC) curve, sensitivity, selectivity, specificity, positive predictive value (PPV), and negative predictive value (NPV) were calculated.

For GC-TOF-MS data analysis, the data was processed using the TOF-DS software. A background correction was applied, and the chromatogram was integrated using TOF-DS. The peaks from the chromatogram were identified using the NIST (National Institute of Standards and Technology) list. The TOF-DS software is used to identify chemicals and their abundance in the sample. The chemical identification for GC-TOF-MS data was done based on a $p$-value less than 0.05 . These chemicals were then compared with published papers and PubChem. For R analysis, the data obtained from GC-TOF-MS was converted into text files. These files were then used to generate statistical probabilities using $\mathrm{R}$ program (version 3.6.2) in a similar process as for the PEN3 and chemical components of discriminative power were identified. Figure 1 illustrates the step taken for analysing the data. 


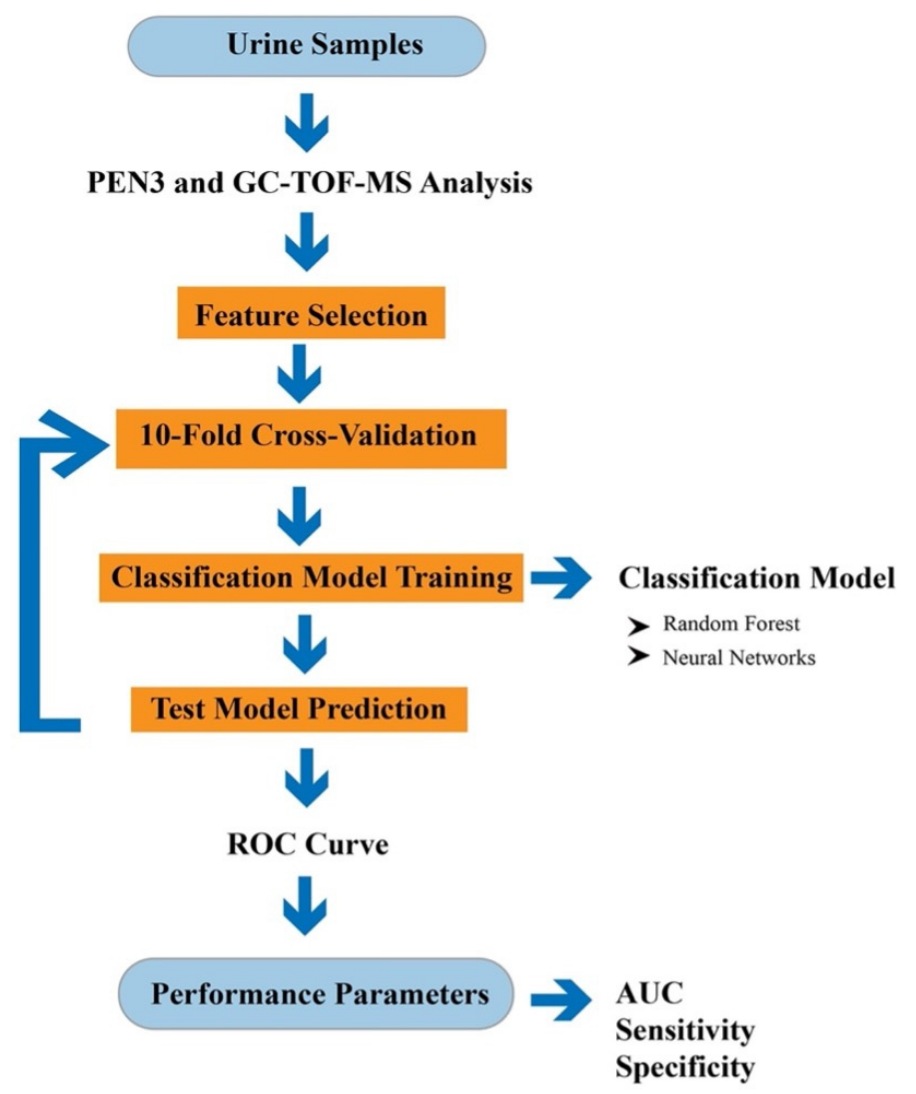

Figure 1. Flowchart of the data analysis used in this study.

\section{Results}

3.1. Evaluation by Electronic Nose Detection Method

The PEN3 contains 10 gas sensors, the raw output of each of the sensors to a late CRC urine sample is shown in Figure 2. Each coloured line in the output represents the response curve of one of the sensors.

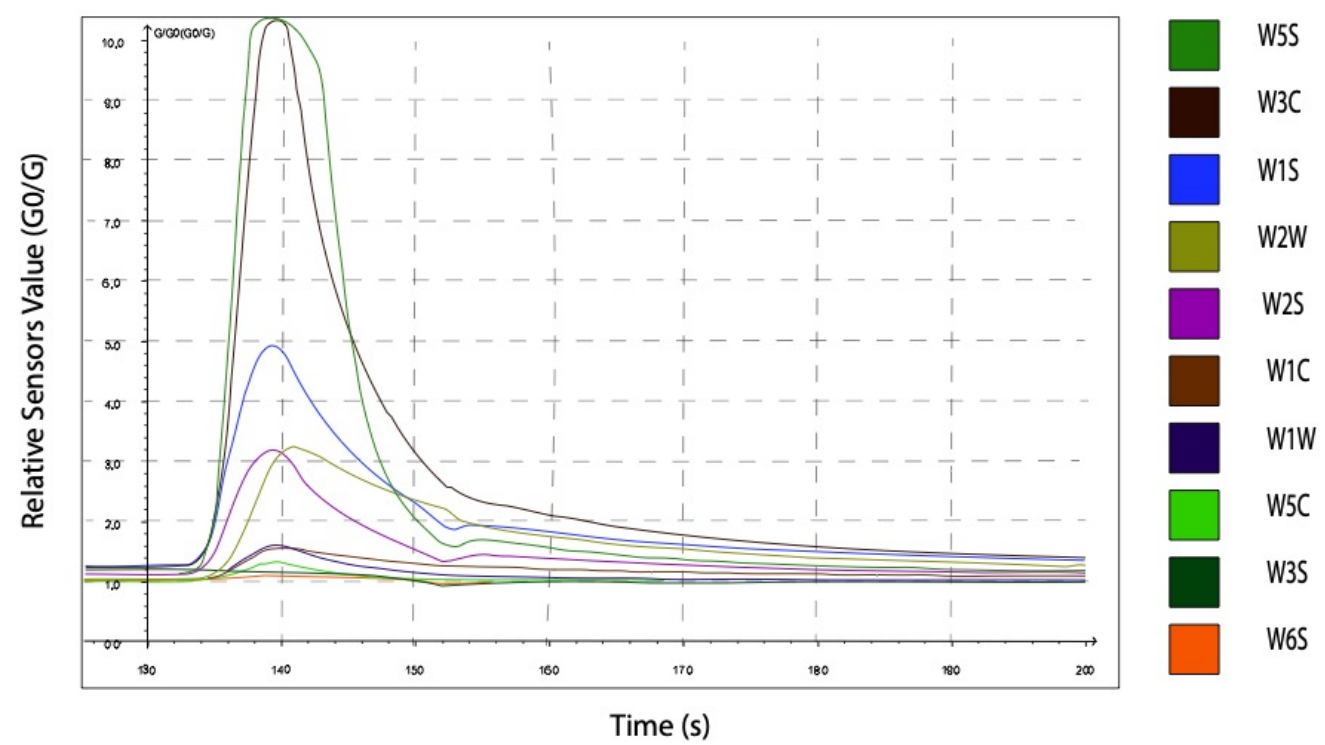

Figure 2. Typical output of the PEN3 to a late CRC urine samples, where each curve representing output from a different sensor. 
Radar plot shown in Figure 3 represents the average response of PEN3 sensors to the two groups. Radar plot compared sensors response for CRC (red line) and non-cancerous sample (yellow line).

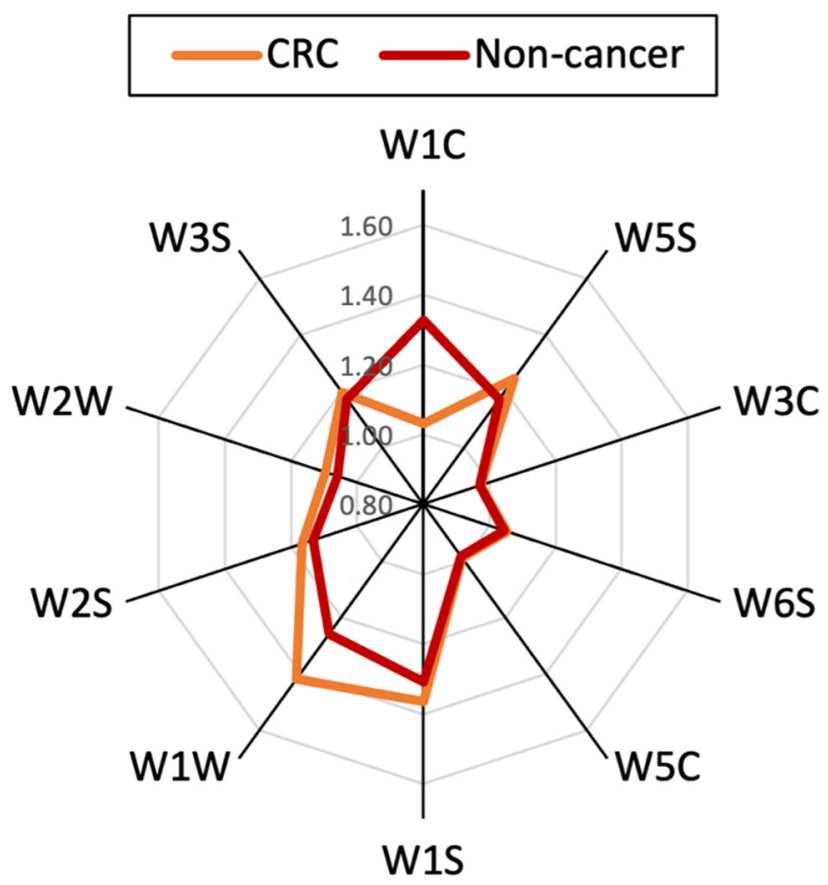

Figure 3. Radar plot of the output features of the PEN3 to a CRC and control sample.

Radar plot in Figure 4 shows the average response of the sensors corresponding to the early-stage CRC (green line), late-stage CRC (orange line), and non-cancer group (red line).
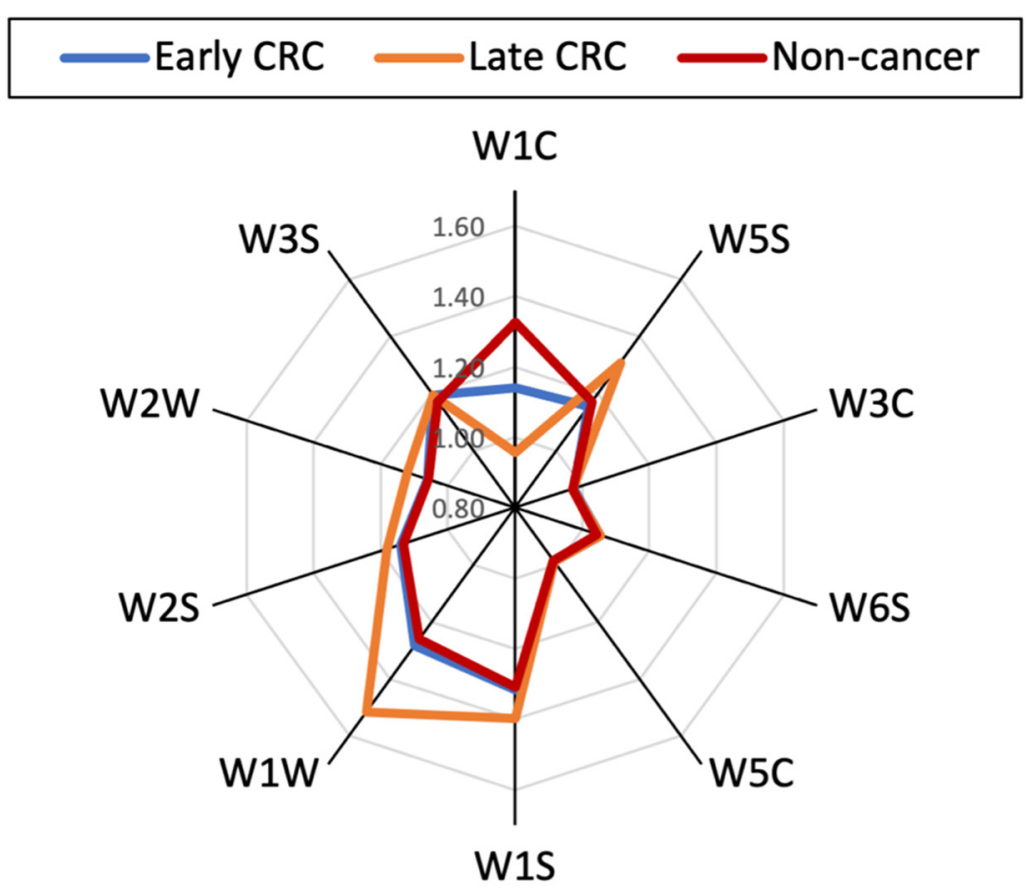

Figure 4. Radar plot of the output features of the PEN3 to an early-stage CRC, late-stage CRC, and control sample. 
The results obtained from statistical analysis of PEN3 data validated the separation of the CRC and non-cancerous group based upon the chemicals present in the samples. The results are shown in Table 3.

Table 3. Statistical Results for PEN3 with 95\% confidence intervals in brackets.

\begin{tabular}{ccccccc}
\hline Classifiers & Comparisons & AUC & Sensitivity & Specificity & PPV & NPV \\
\hline Neural & CRC vs. & 0.81 & 0.91 & 0.55 & 0.76 & 0.81 \\
Network & Non-Cancerous & $(0.73-0.88)$ & $(0.85-0.97)$ & $(0.41-0.69)$ & $(0.61-0.84)$ & $(0.67-0.93)$ \\
Random & CRC vs. & 0.80 & 0.82 & 0.55 & 0.74 & 0.68 \\
Forest & Non-Cancerous & $(0.72-0.87)$ & $(0.74-0.90)$ & $(0.41-0.68)$ & $(0.65-0.83)$ & $(0.53-0.82)$ \\
\hline
\end{tabular}

The receiver operating characteristics curves (ROC) of the two models used to obtain highest AUC are shown in Figure 5. The results from R analysis on PEN3 output differentiated CRC from Non-cancerous group with a high sensitivity of $0.91(0.85-0.97)$, specificity of 0.55 (0.41-0.69), and AUC of $0.81(0.73-0.88)$ using a Neural Network.

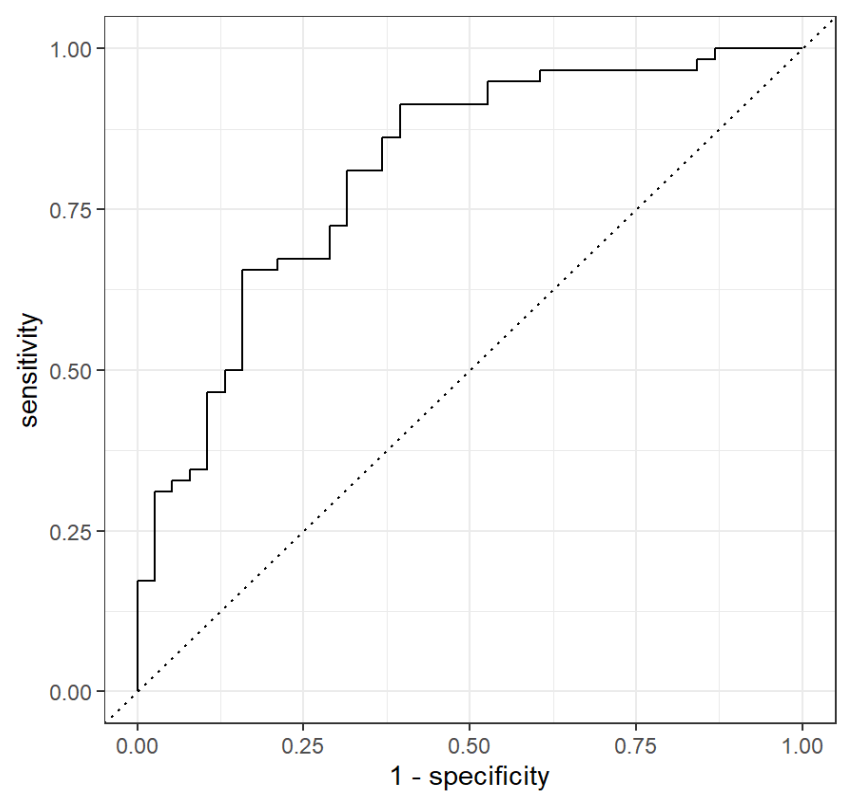

(a)

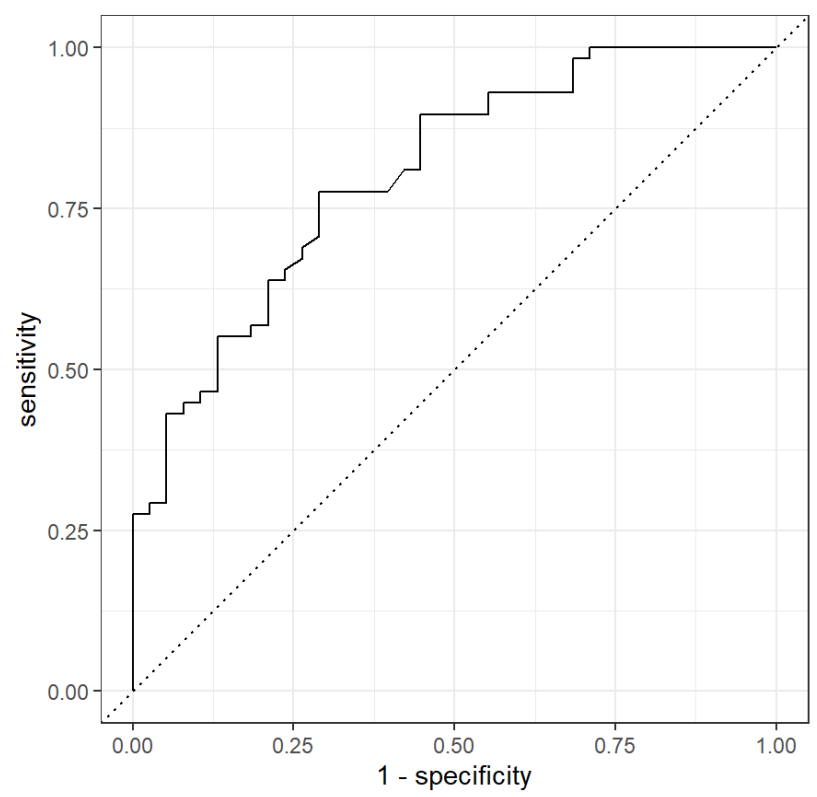

(b)

Figure 5. ROC for CRC vs. Non-Cancerous using (a) Neural Network and (b) Random Forest classifiers for PEN3.

\subsection{Evaluation by GC-TOF-MS Detection Method}

Figure 6 provides an example output from the GC-TOF-MS. Here, the x-axis refers to the retention time, and the y-axis, the total ion count.

GC-TOF-MS shows a very high separation among the two groups, as shown in Table 4. The results illustrate that GC-TOF-MS was able to separate cancer and non-cancerous groups with a very high sensitivity and specificity. 


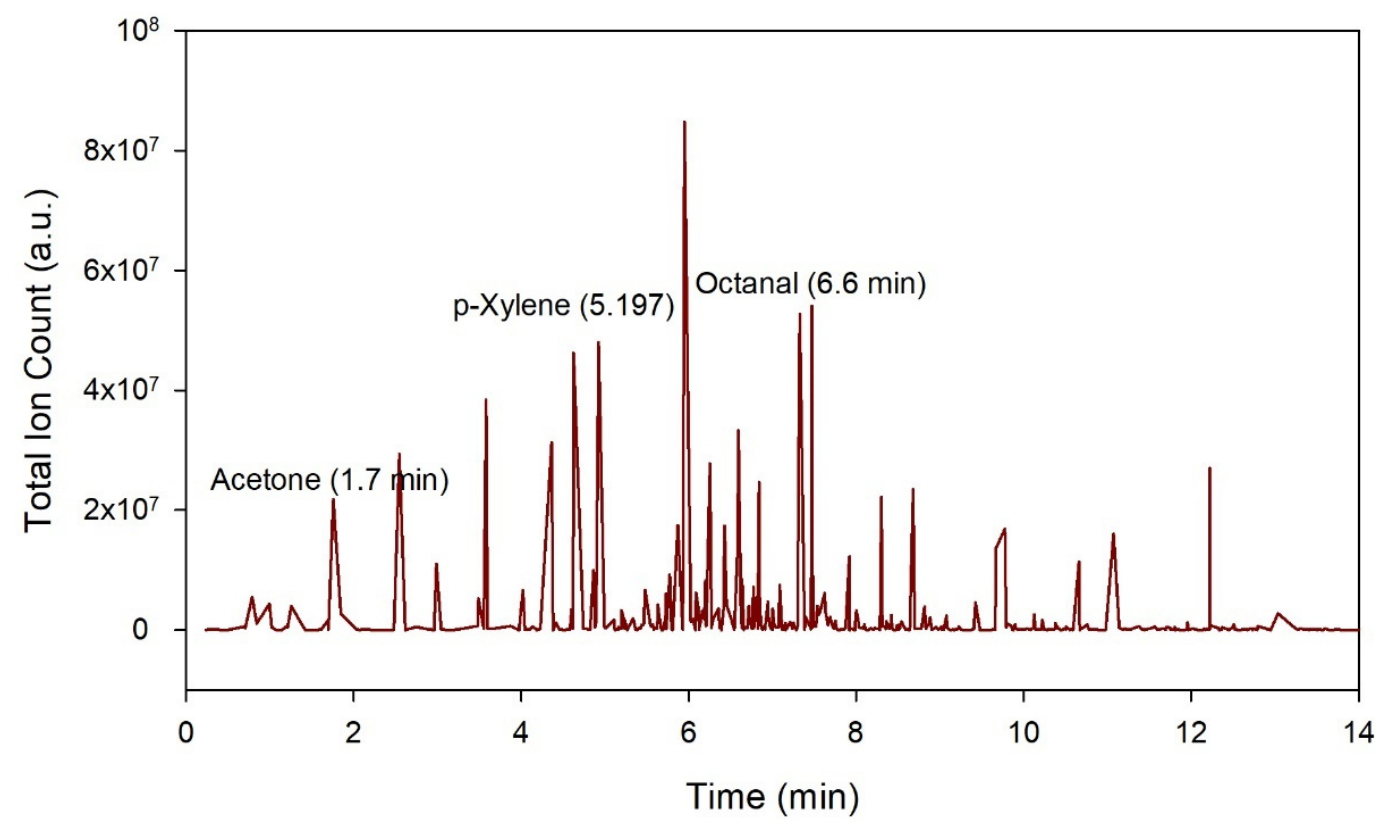

Figure 6. Output from the GC-TOF-MS to a late CRC urine sample with each peak representing the abundance of the chemicals at retention time.

Table 4. Statistical Results for GC-TOF-MS with 95\% confidence intervals in brackets.

\begin{tabular}{ccccccc}
\hline Classifiers & Comparisons & AUC & Sensitivity & Specificity & PPV & NPV \\
\hline Neural & CRC vs. & 0.93 & 0.86 & 0.81 & 0.91 & 0.79 \\
Network & Non-Cancerous & $(0.89-0.97)$ & $(0.79-0.93)$ & $(0.77-0.95)$ & $(0.84-0.97)$ & $(0.69-0.89)$ \\
Random & CRC vs. & 0.93 & 0.89 & 0.75 & 0.85 & 0.82 \\
Forest & Non-Cancerous & $(0.88-0.96)$ & $(0.83-0.96)$ & $(0.62-0.86)$ & $(0.77-0.92)$ & $(0.71-0.93)$ \\
\hline
\end{tabular}

For CRC and non-cancerous group with Neural network classifier, the sensitivity was 0.86 (0.78-0.93), specificity was $0.86(0.77-0.95)$, and AUC was 0.93 (0.89-0.97). Figure 7 represents the ROC curves for GC-TOF-MS.

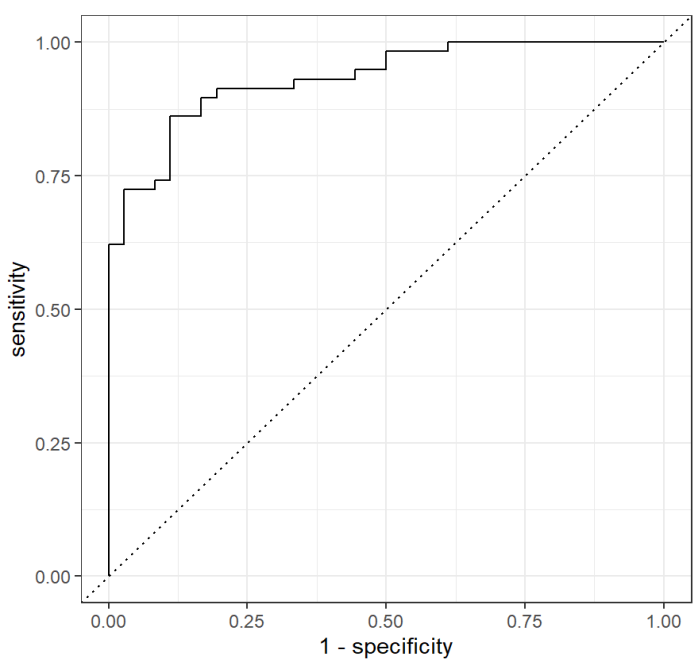

(a)

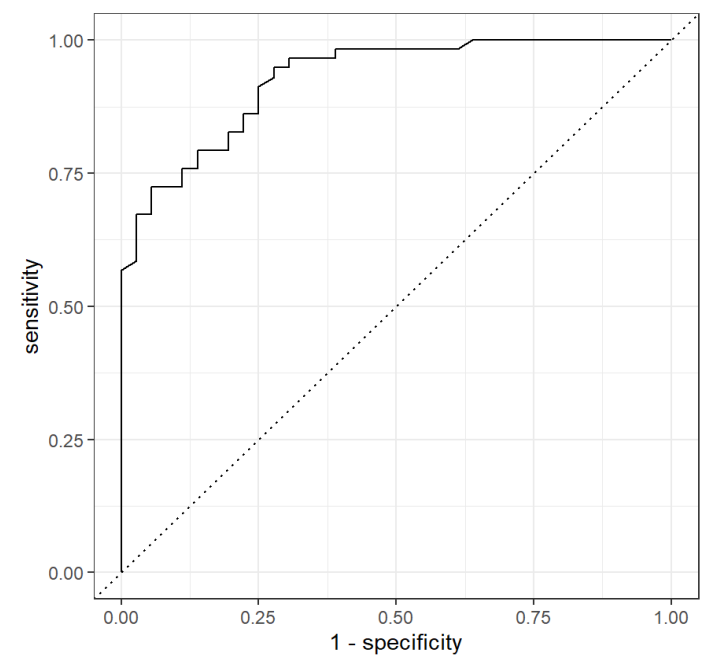

(b)

Figure 7. ROC for CRC vs. non-Cancerous using (a) Neural Network and (b) Random Forest classifiers for GC-TOF-MS.

In addition, data obtained from GC-TOF-MS was used to identify the unknown VOCs in the urine sample headspace. The TOF-DS software identified the chemicals based on 
NIST list using a criterion of $p$-value $<0.05$. We were able to identify 23 VOCs for CRC and non-cancer comparison shown in Table 5. We were able to cross-verify a total of 11 CRC VOCs from different studies and PubChem as shown in Table 5.

Table 5. VOCs obtained from GC-TOF-MS data analysis using the TOF-DS software.

\begin{tabular}{|c|c|c|c|}
\hline S. No. & Chemicals & Retention time (s) & $p$-Value \\
\hline 1 & Octanal $^{\mathrm{a}}$ & 6.5851 & $<0.001$ \\
\hline 2 & Nonanal a & 7.4723 & $<0.001$ \\
\hline 3 & Decanal $^{\mathrm{a}}$ & 7.5505 & $<0.001$ \\
\hline 4 & 2,4-Di-tert-butylphenol & 10.6607 & $<0.001$ \\
\hline 5 & Heptanal a & 5.6302 & $<0.001$ \\
\hline 6 & Heptadecane & 10.3784 & $<0.001$ \\
\hline 7 & Undecanal & 9.08 & $<0.001$ \\
\hline 8 & 3,4-Dimethylcyclohexanol & 9.6693 & $<0.001$ \\
\hline 9 & 5-Hepten-2-ol, 6-methyl- & 9.7753 & $<0.001$ \\
\hline 10 & Hexanal $^{\mathrm{a}}$ & 4.6015 & $<0.001$ \\
\hline 11 & Acetone ${ }^{\mathrm{a}}$ & 1.6974 & $<0.001$ \\
\hline 12 & 2-Pentanone ${ }^{a}$ & 3.4864 & 0.001 \\
\hline 13 & Biphenyl & 9.7844 & 0.003 \\
\hline 14 & 2-Heptanone ${ }^{\mathrm{a}}$ & 5.5489 & 0.00429 \\
\hline 15 & Cyclopentanone, 2-methyl- & 5.772 & 0.00453 \\
\hline 16 & Ethylbenzene ${ }^{a}$ & 5.107 & 0.00499 \\
\hline 17 & Methane, isocyanato- & 1.4175 & 0.00666 \\
\hline 18 & Acetophenone & 7.3934 & 0.00888 \\
\hline 19 & 1-Undecanol & 9.6614 & 0.01307 \\
\hline 20 & p-Xylene ${ }^{a}$ & 5.197 & 0.01478 \\
\hline 21 & $\begin{array}{c}\text { Benzene, } \\
\text { 1-methyl-3-(1-methylethyl)- }\end{array}$ & 6.6649 & 0.01602 \\
\hline 22 & Naphthalene ${ }^{a}$ & 8.3504 & 0.02613 \\
\hline 23 & Octane, 2,2,6-trimethyl- & 5.8677 & 0.04052 \\
\hline
\end{tabular}

${ }^{a}$ represents the chemicals for the identification of CRC cross-verified using PubChem and published papers.

Comparisons were also performed on the CRC samples according to the stage of cancer for the quantitative determination of VOCs among the stages. Table 6 illustrates the statistical result obtained for different stages of CRC and non-cancer samples using $R$ analysis using the data obtained from PEN3. Both Random Forest and Neural Network classifiers were used. These gave similar results, with the best result provided in Table 6 .

Table 6. Statistical Results for CRC stage comparisons with $95 \%$ confidence intervals in brackets using PEN3.

\begin{tabular}{ccccccc}
\hline Classifiers & Comparisons & AUC & Sensitivity & Specificity & PPV & NPV \\
\hline Neural & Early vs. & 0.67 & 0.48 & 0.84 & 0.65 & 0.73 \\
Network & Non-Cancer & $(0.54-0.79)$ & $(0.30-0.65)$ & $(0.74-0.93)$ & $(0.44-0.83)$ & $(0.61-0.83)$ \\
Random & Early vs. & 0.78 & 0.61 & 0.84 & 0.70 & 0.78 \\
Forest & Non-Cancer & $(0.66-0.87)$ & $(0.43-0.76)$ & $(0.74-0.94)$ & $(0.52-0.86)$ & $(0.67-0.88)$ \\
Neural & Late vs. & 0.85 & 0.65 & 0.82 & 0.76 & 0.72 \\
Network & Non-Cancerous & $(0.78-0.92)$ & $0.51-0.78)$ & $(0.71-0.92)$ & $(0.63-0.89)$ & $(0.61-0.83)$ \\
Random & Late vs. & 0.76 & 0.74 & 0.66 & 0.66 & 0.74 \\
Forest & Non-Cancerous & $(0.66-0.84)$ & $(0.61-0.85)$ & $(0.53-0.79)$ & $(0.53-0.79)$ & $(0.61-0.85)$ \\
Neural & Early vs. Late & 0.61 & 0.68 & 0.39 & 0.62 & 0.45 \\
Network & CRC & $(0.49-0.73)$ & $(0.54-0.81)$ & $(0.22-0.56)$ & $(0.49-0.75)$ & $(0.26-0.64)$ \\
Random & Early vs. Late & 0.59 & 0.71 & 0.39 & 0.63 & 0.48 \\
Forest & CRC & $(0.45-0.71)$ & $(0.57-0.83)$ & $(0.22-0.56)$ & $(0.50-0.76)$ & $(0.28-0.67)$ \\
\hline
\end{tabular}

These results represent that PEN3 was able to distinguish early-stage CRC from noncancer samples and late-stage CRC from non-cancer samples. Out of 24 early-stage CRC samples, PEN3 was able to identify 14 samples correctly, hence, obtaining a sensitivity of 0.70 . While for non-cancer samples, PEN3 recognized 32 out of 38 samples, obtaining a 
specificity of 0.53 . AUC obtained for late-stage CRC and non-cancer samples comparison was 0.85 with a sensitivity and specificity of 0.65 and 0.82 , showing that PEN3 identified 22 CRC samples out of 34 and 31 out of 38 non-cancer samples. However, the results for early-stage CRC and late-stage CRC were moderate with 0.61 AUC, 0.68 sensitivity, and 0.39 specificity. The ROC curves for the statistical analysis of different stages of CRC using the data from PEN3 is shown in Figure 8.

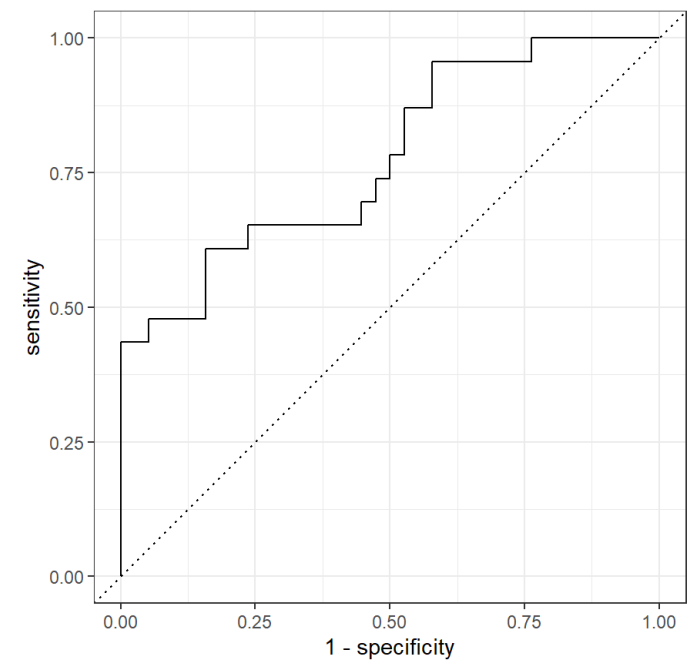

(a)

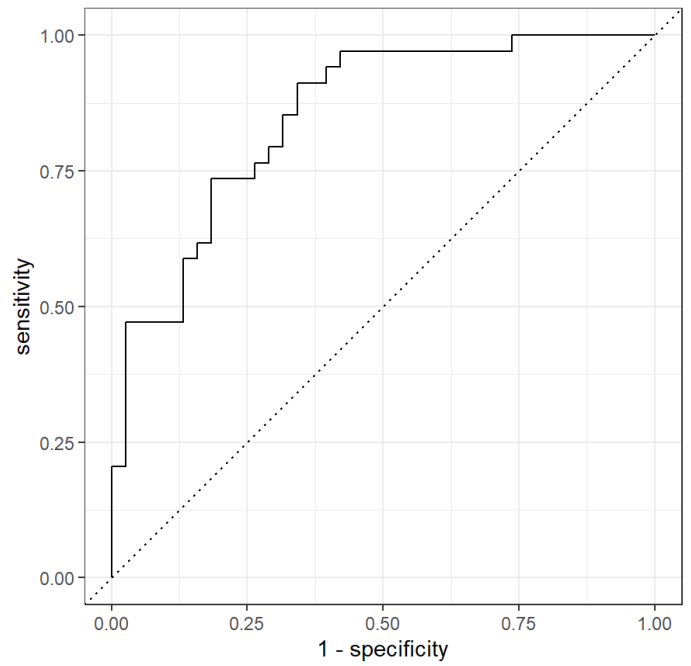

(b)

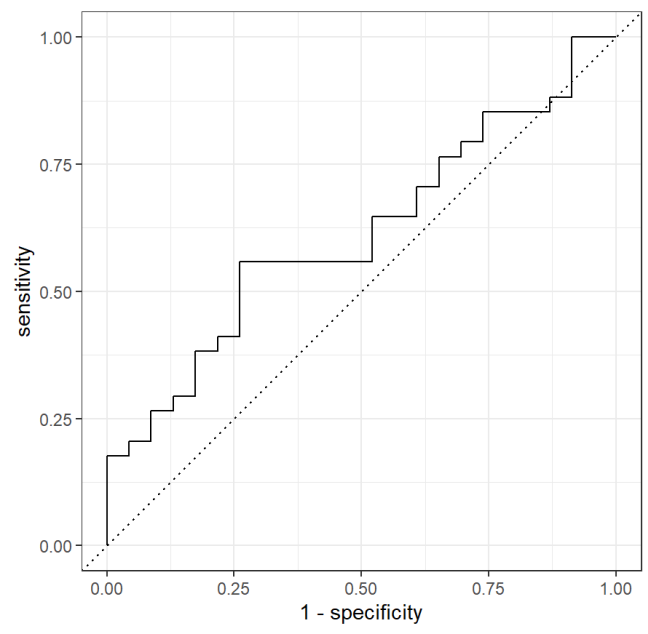

(c)

Figure 8. ROC for different stages of CRC vs. non-Cancer: (a) early-stage CRC vs. non-cancer using Random Forest classifiers, (b) late-stage CRC vs. non-cancer using Neural Network, and (c) early-stage CRC vs. late-stage CRC using Neural Network using the PEN3 analytical device.

The results obtained for the comparison of early-stage CRC, late-stage CRC, and non-cancer samples for GC-TOF-MS data are shown in Table 7.

For the early-stage CRC vs. non-cancer comparison using GC-TOF-MS, results show that out of 24 early-stage CRC samples, 16 were correctly diagnosed as CRC samples giving sensitivity of 0.67 and out of 38 non-cancer samples, 34 samples were correctly recognized as non-cancer samples giving specificity of 0.94 . As for late-stage CRC vs. non-cancer samples, 26 samples out of 34 were correctly diagnosed as CRC samples giving 0.79 sensitivity and 32 samples were correctly recognized as non-caner samples out of 38 giving specificity of 0.89 . However, the results obtained for the comparison between early-stage vs. late-stage were moderate. The sensitivity obtained was 0.46 signifying that 11 earlystage samples were correctly diagnosed, and specificity obtained was 0.61 indicating that 
20 late-stage CRC samples were correctly diagnosed. Figure 9 shows the ROC curves for these comparisons.

Table 7. Statistical Results for CRC stage comparisons with $95 \%$ confidence intervals in brackets using GC-TOF-MS.

\begin{tabular}{|c|c|c|c|c|c|c|}
\hline Classifiers & Comparisons & AUC & Sensitivity & Specificity & PPV & NPV \\
\hline Neural & Early vs. & 0.9 & 0.75 & 0.86 & 0.78 & 0.84 \\
\hline Network & Non-Cancer & $(0.83-0.96)$ & $(0.59-0.89)$ & $(0.76-0.95)$ & $(0.64-0.92)$ & $(0.73-0.93)$ \\
\hline Random & Early vs. & 0.93 & 0.67 & 0.94 & 0.89 & 0.81 \\
\hline Forest & Non-Cancer & $(0.87-0.96)$ & $(0.5-0.82)$ & $(0.88-1)$ & $(0.75-1)$ & $(0.71-0.90)$ \\
\hline Neural & Late vs. & 0.89 & 0.79 & 0.89 & 0.87 & 0.82 \\
\hline Network & Non-Cancerous & $(0.81-0.96)$ & $(0.67-0.90)$ & $(0.79-0.97)$ & $(0.76-0.97)$ & $(0.72-0.92)$ \\
\hline Random & Late vs. & 0.86 & 0.73 & 0.81 & 0.77 & 0.76 \\
\hline Forest & Non-Cancerous & $(0.78-0.93)$ & $(0.59-0.83)$ & $(0.68-0.91)$ & $(0.64-0.89)$ & $(0.65-0.8)$ \\
\hline Neural & Early vs. Late & 0.56 & 0.46 & 0.61 & 0.46 & 0.61 \\
\hline Network & CRC & $(0.43-0.69)$ & $(0.29-0.63)$ & $(0.46-0.74)$ & $(0.29-0.62)$ & $0.43-0.74)$ \\
\hline Random & Early vs. Late & 0.56 & 0.38 & 0.69 & 0.47 & 0.61 \\
\hline Forest & $\mathrm{CRC}$ & $(0.43-0.69)$ & $(0.22-0.55)$ & $(0.56-0.83)$ & $(0.29-0.67)$ & $(0.43-0.74)$ \\
\hline
\end{tabular}

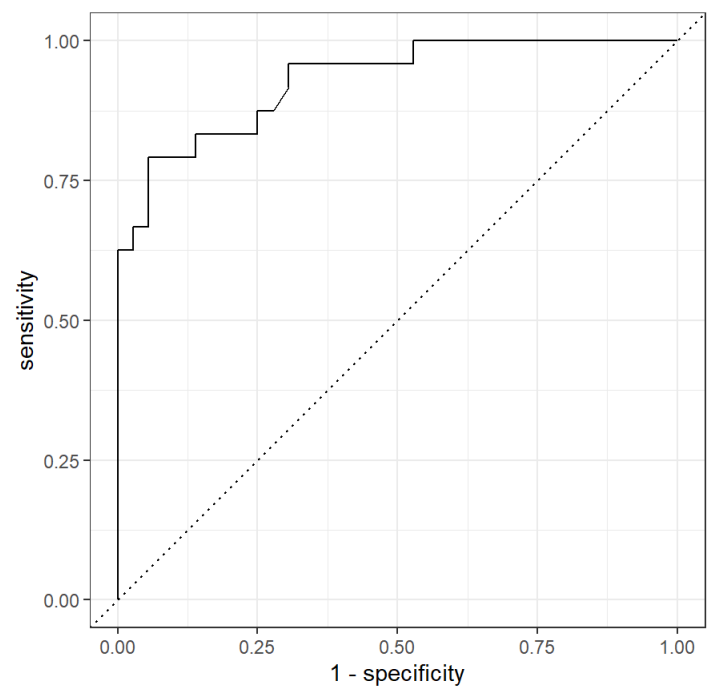

(a)

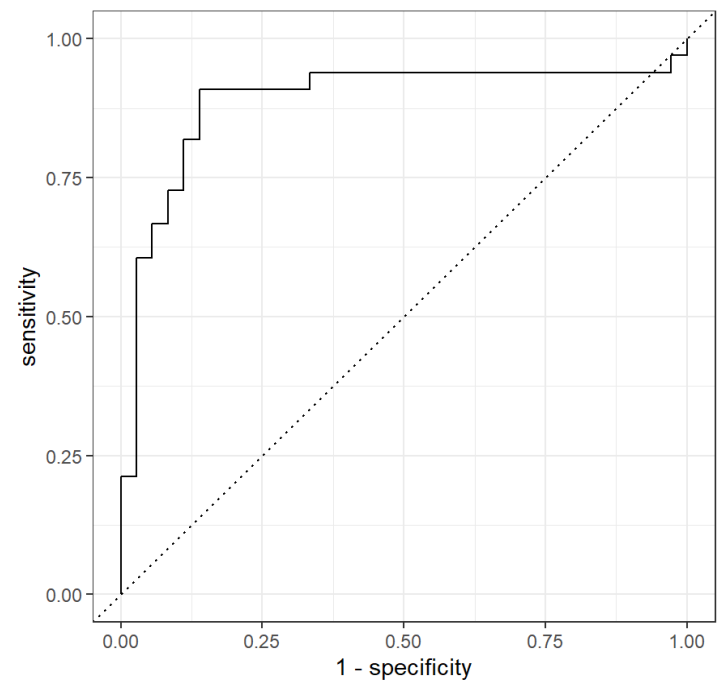

(b)

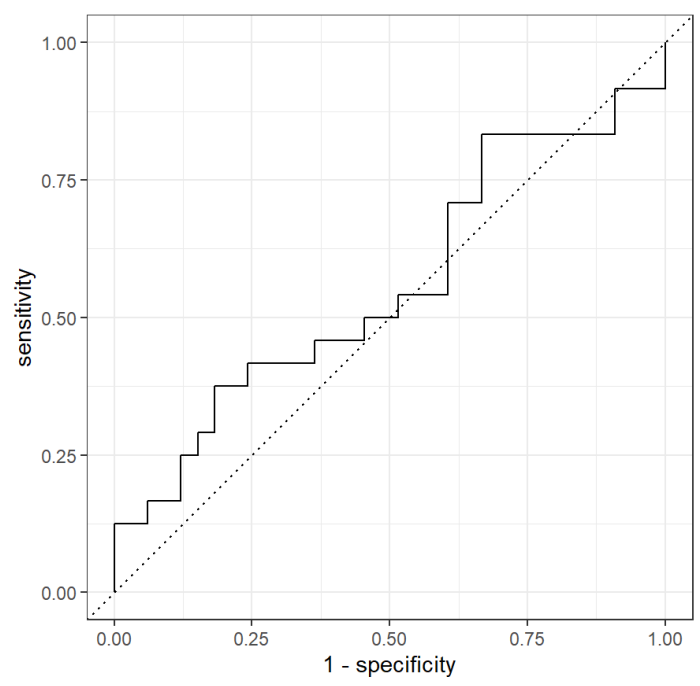

(c)

Figure 9. ROC for different stages of CRC vs. non-Cancer: (a) early-stage CRC vs. non-cancer using Random Forest classifiers, (b) late-stage CRC vs. non-cancer using Neural Network, and (c) early-stage CRC vs. late-stage CRC using Neural Network using the GC-TOF-MS analytical device. 
A quantitative comparison of the chemical's concentration was performed for different stages of CRC and non-cancer samples. Figure 10 illustrates the result obtained. The result shows that the chemicals follow a pattern for early-stage CRC, late-stage CRC, and noncancer samples.

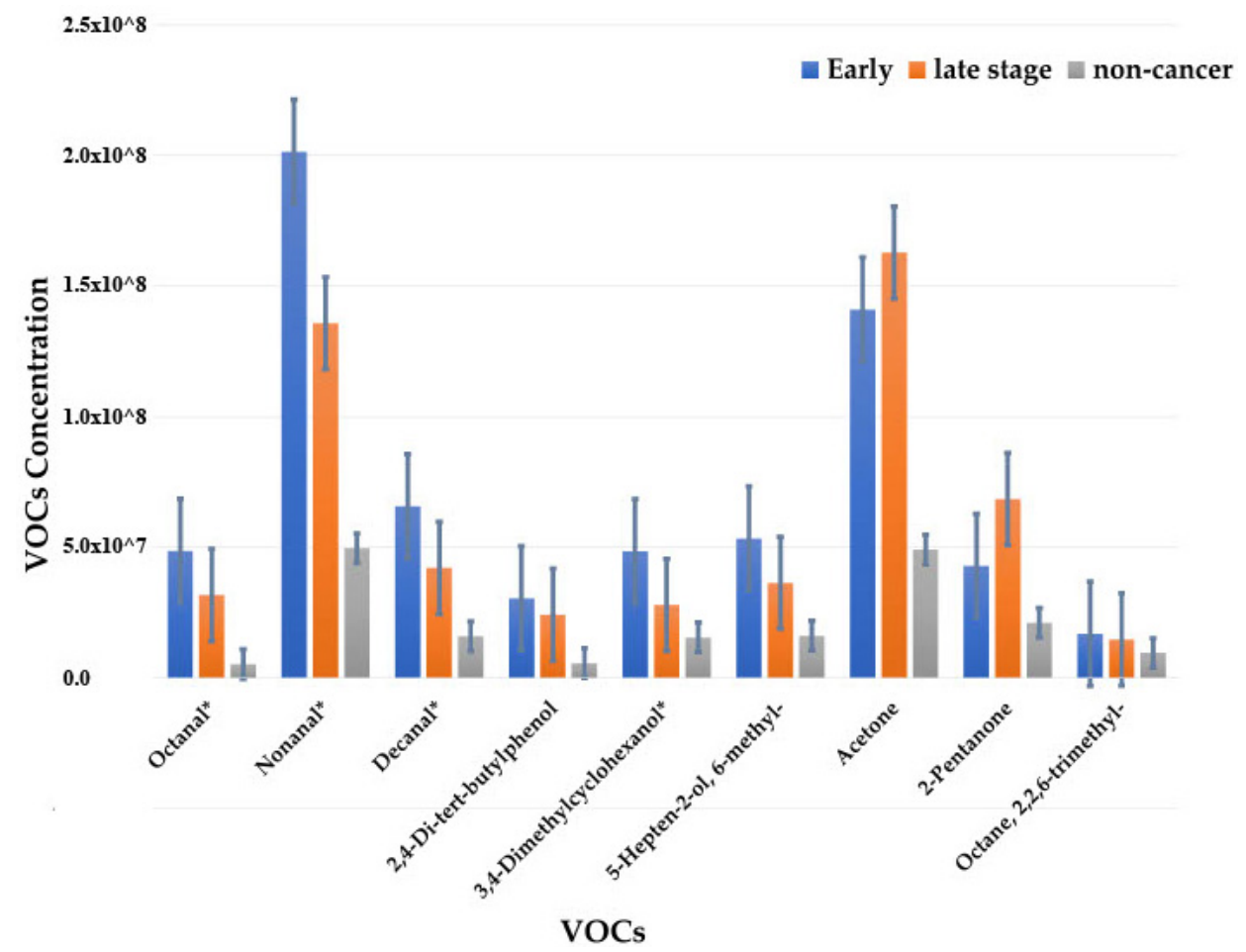

Figure 10. Bar graph for the VOCs present in the study with their respective average concentration among early-stage CRC, late-stage CRC, and non-cancer samples. The * mark represents statistically significant VOCs.

\section{Discussion}

A number of studies have previously demonstrated the use of urinary headspace VOCs for the detection of different cancers, as well as other diseases [51,52]. Detection of cancer using VOCs is of great interest as it is non-invasive and potentially inexpensive. In this study, we have determined that cancer group can be differentiated from a non-cancer group based on their chemical fingerprints. We used two approaches for distinguishing CRC and the non-cancer group, specifically PEN3 e-nose and GC-TOF-MS. Both methods demonstrated a high accuracy of separation between the groups. We also identified the chemical compounds in the urinary VOC profile for CRC using GC-MS-TOF data.

PEN3 showed promising results with high sensitivity and specificity. The PEN3 was able to differentiate CRC and non-cancer group using Neural Network classifier with AUC of 0.81 and very high sensitivity of 0.91 and specificity of 0.55 . The separation between CRC and non-cancer group using Random Forest classifier was reported 0.80 AUC, 0.82 sensitivity and 0.55 specificity.

The AUC obtained by GC-TOF-MS for CRC and non-cancer group was 0.93 with both the classifiers. The sensitivity obtained between the groups was 0.86 for Neural Network classifier and 0.89 for Random Forest. These are very high values showing that GC-TOF-MS was able to recognise and separate CRC and non-cancer urine samples.

Table 5 shows all the chemicals identified by TOF-DS software of which, octanal, nonanal, decanal, heptanal, hexanal, and acetone had the highest significance with a $p$ value of $<0.001$. Other possible significant biomarkers were 2-pentanone, 2-heptanone, ethylbenzene, $\mathrm{p}$-xylene, naphthalene.

Octanal is a human metabolite present in cell membrane and generally reported in saliva or faeces [53]. It was reported by Batty et al. on analysis of faecal samples of CRC 
with PLS-DA following feature selection with Wilcoxon T test [54]. Nonanal is a toxic compound and has been found related with several diseases. It may lead to kidney disease, comas, uraemia, seizures, nausea, confusion, and cardiovascular diseases and has been found in faeces, blood, and saliva from humans [53]. Nonanal has frequently been reported as a breath biomarker for CRC in different studies [55-57]. Decanal is another important biomarker observed in our study, which has been reported as a CRC biomarker in several studies as a breath biomarker [55,57] and in cell culture studies [58-60]. Heptanal has been identified as a faecal and urinary biomarker for CRC in two different studies [54,61]. Hexanal $[55,58]$ and acetone $[44,58,62]$ were also reported as significant biomarker for CRC.

2-Pentanone is generally present in milk $[61,63]$ and different foods and found in cytoplasm and extracellular places in human body. 2-Pentanone has been reported as CRC biomarkers by Arasaradnam et al. in their study of colorectal cancer using urinary samples [62]. 2-Heptanone exists at cell membrane level inside living species including humans, and outside, it can be found in milk, corns, and peppermints. It causes hepatic encephalopathy [64] and can be found in saliva, faeces, urine, and cerebrospinal fluid [53]. It has been identified as a significant CRC biomarker using cell culture in two different studies [58,60]. Another important biomarker we found was p-Xylene. p-Xylene has several physiological effects such as drowsiness, paralysis, coma, dizziness, anaemia, hypertension, pain, fatigue, headache, depression, and anxiety. It is an air pollutant and environmental contaminant [53]. It is reported as a CRC VOC in three different studies $[55,57,65]$.

Ethylbenzene is a human metabolite present in subcellular level (membrane) in the human body. It causes dizziness, pain, headache, cough, hepatitis, and drowsiness. It is present in tobacco smoke and is water and air pollutant [53]. De Vietro et al. found that ethylbenzene was present in four out of the seven CRC patients breath samples and tissue samples [56]. Furthermore, study conducted by Altomare et al. showed that ethylbenzene was associated with chemical fingerprint of CRC [66]. Naphthalene has also been suggested as a CRC biomarker in PubChem.

For the PEN3, it is not possible to identify specific chemical biomarkers for CRC. It is worth noting that the sensors which are likely to comprise the PEN3 will be sensitive to both inorganic gases as well as VOCs. In fact, one of the sensors that show a significant difference has increased sensitivity to sulphur compounds. In is worth noting that the preconcentration approach used here for GC-TOF-MS analysis, limits our range of detection to molecules with more than three carbon atoms. Therefore, the chemical components being measured by the PEN3 and by GC-TOF-MS may not be the same. Furthermore, the gas sensors used in the PEN3 are likely to have cross-sensitivity to a range of inorganic gases. Therefore, the response could be associated with VOCs, inorganic gases, or a combination of both. In the future, we hope to analyse further these chemicals to understand their contribution to the instrument's diagnostic potential.

A comparison was performed between the different stages of CRC in this study. CRC samples were divided into early-stage CRC and late-stage CRC depending on the TNM staging of each sample. Each sample was assigned T1 to T4 stage depending upon the size and/or extent of the tumour. T1 and T2 were grouped as early-stage cancer and T3 and T4 were grouped as late-stage cancer. These comparisons were performed for both PEN3 and GC-TOF-MS data. The results illustrate that PEN3 was able to separate early-stage CRC and late-stage $\mathrm{CRC}$ from non-cancer samples with higher statistical output in comparison to the early-stage CRC versus late-stage CRC. A similar pattern was observed for GC-TOF-MS data. Though the results obtained by GC-TOF-MS data showed greater separation with higher sensitivity and specificity.

However, the results from the comparison of two stages based on concentration of chemicals found in the study demonstrate high capability of GC-TOF-MS to distinguish the two stages of CRC. Figure 9 illustrates that early-stage, late-stage, and non-cancer samples have different level of concentrations of VOCs. The statistically significant chemicals for this separation, i.e., chemicals with a $p$-value of $<0.05$, were represented by the ${ }^{*}$ mark. This signifies that the detection of the cancer and the stages of the CRC based on VOCs profile 
may be a possible diagnosis method. The PEN3 was unable to accurately separate early from late-stage cancer. This may be associated with ability of this system to measure the subtle differences between early and late-stage cancer.

The study limitations were relatively small sample size/single centre study and lack of comparison with healthy control group. We compared cancer group with non-cancer group (patients with history of bowel symptoms suggestive of cancer but subsequently excluded). Another limitation was that no chemical identification was undertaken with calibration standards, and we did not attempt to quantify these chemicals. However, many of the chemicals were reported in other studies and therefore, suggests consistency in reporting.

\section{Conclusions}

In our study, we investigated the use of PEN3 and GC-TOF-MS for the analysis of urinary headspace biomarkers for colorectal cancer. We found that both PEN3 and GC-TOFMS were successful in separating the groups with high AUC. For the PEN3, the highest AUC was seen for CRC and non-cancer group, AUC was 0.81 (0.73-0.88) and GC-TOF-MS demonstrated relatively higher sensitivity and specificity with AUC for CRC and noncancer group $0.93(0.89-0.97)$. The TOF-DS software was then used to investigate the VOCs linked with both the cancers using GC-TOF-MS data. We found a total of 23 VOCs, out of which 11 were cross verified using published papers and PubChem. This VOC profile may support the use of VOCs for the screening of cancer and confirm clinical diagnostic assessments. This will help in avoiding inefficient analytical methods currently used for screening and give better, cheaper, and non-invasive approach for cancer diagnosis and detection. Further, we verified that e-nose can be used for the detection and diagnosis of cancer as it demonstrates high sensitivity and specificity.

Author Contributions: Conceptualization, H.T., J.A.C. and R.P.A.; methodology, H.T. and E.D.; formal analysis, H.T.; investigation, H.T. and E.D.; resources, A.S.B., J.A.C. and R.P.A.; data curation, H.T. and A.S.B.; writing — original draft preparation, H.T.; writing — review and editing, H.T., E.D., A.S.B., R.P.A. and J.A.C.; visualization, H.T. and J.A.C.; supervision, J.A.C. and R.P.A. All authors have read and agreed to the published version of the manuscript.

Funding: This research received no external funding.

Institutional Review Board Statement: The study was conducted according to the guidelines of the Declaration of Helsinki and approved by the Institutional Review Board (or Ethics Committee) by Coventry and Warwickshire and North-East Yorkshire NHS Ethics Committees (Ref 18717 and Ref 260179).

Informed Consent Statement: The study was approved by Coventry and Warwickshire and NorthEast Yorkshire NHS Ethics Committees (Ref 18717 and Ref 260179). Written informed consent has been obtained from the patients to publish this paper.

Data Availability Statement: All data are available from this manuscript.

Acknowledgments: This research did not receive any specific grant from funding agencies in the public, commercial, or not-for-profit sectors.

Conflicts of Interest: The authors declare no conflict of interest.

\section{References}

1. Sung, H.; Ferlay, J.; Siegel, R.L.; Laversanne, M.; Soerjomataram, I.; Jemal, A.; Bray, F. Global cancer statistics 2020: GLOBOCAN estimates of incidence and mortality worldwide for 36 cancers in 185 countries. CA Cancer J. Clin. 2021, 71, 209-249. [CrossRef]

2. Jayanthi, V.S.P.K.S.A.; Das, A.B.; Saxena, U. Recent advances in biosensor development for the detection of cancer biomarkers. Biosens. Bioelectron. 2017, 91, 15-23. [CrossRef] [PubMed]

3. Gao, Q.; Lee, W.-Y. Urinary metabolites for urological cancer detection: A review on the application of volatile organic compounds for cancers. Am. J. Clin. Exp. Urol. 2019, 7, 232-248. [PubMed]

4. Amann, A.; Smith, D. Volatile Biomarkers: Non-Invasive Diagnosis in Physiology and Medicine; Elsevier: Oxford, UK, 2013; ISBN 0444626204.

5. Arasaradnam, R.P.; Covington, J.A.; Harmston, C.; Nwokolo, C.U. Review article: Next generation diagnostic modalities in gastroenterology_Gas phase volatile compound biomarker detection. Aliment. Pharmacol. Ther. 2014, 39, 780-789. [CrossRef] 
6. Chandrapalan, S.; Arasaradnam, R.P. Urine as a biological modality for colorectal cancer detection. Expert Rev. Mol. Diagn. 2020, 20, 489-496. [CrossRef]

7. Pomerantz, A.; Blachman-Braun, R.; Galnares-Olalde, J.A.; Berebichez-Fridman, R.; Capurso-García, M. The possibility of inventing new technologies in the detection of cancer by applying elements of the canine olfactory apparatus. Med. Hypotheses 2015, 85, 160-172. [CrossRef] [PubMed]

8. Bray, F.; Ferlay, J.; Soerjomataram, I.; Siegel, R.L.; Torre, L.A.; Jemal, A. Global cancer statistics 2018: GLOBOCAN estimates of incidence and mortality worldwide for 36 cancers in 185 countries. CA Cancer J. Clin. 2018, 68, 394-424. [CrossRef] [PubMed]

9. Widlak, M.M.; Neal, M.; Daulton, E.; Thomas, C.L.; Tomkins, C.; Singh, B.; Harmston, C.; Wicaksono, A.; Evans, C.; Smith, S.; et al. Risk stratification of symptomatic patients suspected of colorectal cancer using faecal and urinary markers. Colorectal Dis. 2018, 20, O335-O342. [CrossRef]

10. Gutierrez-Stampa, M.A.; Aguilar, V.; Sarasqueta, C.; Cubiella, J.; Portillo, I.; Bujanda, L. Colorectal Cancer Survival in 50- to 69-Year-Olds after Introducing the Faecal Immunochemical Test. Cancers 2020, 12, 2412. [CrossRef]

11. Widlak, M.M.; Thomas, C.L.; Thomas, M.G.; Tomkins, C.; Smith, S.; O'Connell, N.; Wurie, S.; Burns, L.; Harmston, C.; Evans, C.; et al. Diagnostic accuracy of faecal biomarkers in detecting colorectal cancer and adenoma in symptomatic patients. Aliment. Pharmacol. Ther. 2017, 45, 354-363. [CrossRef]

12. Chandrapalan, S.; Bosch, S.; Cubiella, J.; Guardiola, J.; Kimani, P.; Mulder, C.; Persaud, K.; de Meij, T.G.J.; Altomare, D.F.; Brenner, H.; et al. Systematic review with meta-analysis: Volatile organic compound analysis to improve faecal immunochemical testing in the detection of colorectal cancer. Aliment. Pharmacol. Ther. 2021, 54, 14-23. [CrossRef]

13. Garborg, K.; Holme, Ø.; Løberg, M.; Kalager, M.; Adami, H.O.; Bretthauer, M. Current status of screening for colorectal cancer. Ann. Oncol. 2013, 24, 1963-1972. [CrossRef]

14. Baxter, N.N.; Goldwasser, M.A.; Paszat, L.F.; Saskin, R.; Urbach, D.R.; Rabeneck, L. Association of Colonoscopy and Death From Colorectal Cancer. Ann. Intern. Med. 2009, 150, 1-8. [CrossRef] [PubMed]

15. Chen, X.; Cao, M.; Li, Y.; Hu, W.; Wang, P.; Ying, K.; Pan, H. A study of an electronic nose for detection of lung cancer based on a virtual SAW gas sensors array and imaging recognition method. Meas. Sci. Technol. 2005, 16, 1535-1546. [CrossRef]

16. Rauch, S.; Jasny, E.; Schmidt, K.E.; Petsch, B. New vaccine technologies to combat outbreak situations. Front. Immunol. 2018, 9 , 1963. [CrossRef] [PubMed]

17. Grate, J.W. Acoustic Wave Microsensor Arrays for Vapor Sensing. Chem. Rev. 2000, 100, 2627-2648. [CrossRef]

18. Öztürk, S.; Kösemen, A.; Kösemen, Z.A.; Kılınç, N.; Öztürk, Z.Z.; Penza, M. Electrochemically growth of Pd doped ZnO nanorods on QCM for room temperature VOC sensors. Sens. Actuators B Chem. 2016, 222, 280-289. [CrossRef]

19. Leunis, N.; Boumans, M.-L.; Kremer, B.; Din, S.; Stobberingh, E.; Kessels, A.G.H.; Kross, K.W. Application of an electronic nose in the diagnosis of head and neck cancer. Laryngoscope 2014, 124, 1377-1381. [CrossRef]

20. Gardner, J.W.; Shin, H.W.; Hines, E.L. An electronic nose system to diagnose illness. Sens. Actuators B Chem. 2000, 70, 19-24. [CrossRef]

21. Yu, I.-J.; Lee, J.-Y.; Chung, Y.-H.; Kim, K.-J.; Han, J.-H.; Cha, G.-Y.; Chung, W.-G.; Cha, Y.-N.; Park, J.-D.; Lee, Y.-M.; et al. Co-administration of toluene and xylene antagonized the testicular toxicity but not the hematopoietic toxicity caused by ethylene glycol monoethyl ether in Sprague-Dawley rats. Toxicol. Lett. 1999, 109, 11-20. [CrossRef]

22. Vaddiraju, S.; Gleason, K.K. Selective sensing of volatile organic compounds using novel conducting polymer-metal nanoparticle hybrids. Nanotechnology 2010, 21, 125503. [CrossRef]

23. Consales, M.; Campopiano, S.; Cutolo, A.; Penza, M.; Aversa, P.; Cassano, G.; Giordano, M.; Cusano, A. Carbon nanotubes thin films fiber optic and acoustic VOCs sensors: Performances analysis. Sens. Actuators B Chem. 2006, 118, 232-242. [CrossRef]

24. Wilson, A.D. Review of Electronic-nose Technologies and Algorithms to Detect Hazardous Chemicals in the Environment. Procedia Technol. 2012, 1, 453-463. [CrossRef]

25. He, J.; Xu, L.; Wang, P.; Wang, Q. A high precise E-nose for daily indoor air quality monitoring in living environment. Integration 2017, 58, 286-294. [CrossRef]

26. Aleixandre, M.; Lozano, J.; Gutiérrez, J.; Sayago, I.; Fernández, M.J.; Horrillo, M.C. Portable e-nose to classify different kinds of wine. Sens. Actuators B Chem. 2008, 131, 71-76. [CrossRef]

27. Chilo, J.; Pelegri-Sebastia, J.; Cupane, M.; Sogorb, T. E-nose application to food industry production. IEEE Instrum. Meas. Mag. 2016, 19, 27-33. [CrossRef]

28. Li, D.; Lei, T.; Zhang, S.; Shao, X.; Xie, C. A novel headspace integrated E-nose and its application in discrimination of Chinese medical herbs. Sens. Actuators B Chem. 2015, 221, 556-563. [CrossRef]

29. Montuschi, P.; Mores, N.; Trové, A.; Mondino, C.; Barnes, P.J. The Electronic Nose in Respiratory Medicine. Respiration 2013, 85, 72-84. [CrossRef]

30. Kou, L.; Zhang, D.; Liu, D. A Novel Medical E-Nose Signal Analysis System. Sensors 2017, 17, 402. [CrossRef]

31. Bruins, M.; Rahim, Z.; Bos, A.; van de Sande, W.W.J.; Endtz, H.P.; van Belkum, A. Diagnosis of active tuberculosis by e-nose analysis of exhaled air. Tuberculosis 2013, 93, 232-238. [CrossRef]

32. Hariyanto; Sarno, R.; Wijaya, D.R. Detection of diabetes from gas analysis of human breath using e-Nose. In Proceedings of the 2017 11th International Conference on Information \& Communication Technology and System (ICTS), Surabaya, Indonesia, 31 October 2017; pp. 241-246. 
33. McWilliams, A.; Beigi, P.; Srinidhi, A.; Lam, S.; MacAulay, C.E. Sex and Smoking Status Effects on the Early Detection of Early Lung Cancer in High-Risk Smokers Using an Electronic Nose. IEEE Trans. Biomed. Eng. 2015, 62, 2044-2054. [CrossRef]

34. Sanaeifar, A.; ZakiDizaji, H.; Jafari, A.; de la Guardia, M. Early detection of contamination and defect in foodstuffs by electronic nose: A review. TrAC Trends Anal. Chem. 2017, 97, 257-271. [CrossRef]

35. Yan, J.; Guo, X.; Duan, S.; Jia, P.; Wang, L.; Peng, C.; Zhang, S. Electronic Nose Feature Extraction Methods: A Review. Sensors 2015, 15, 27804-27831. [CrossRef]

36. Di Natale, C.; Macagnano, A.; Martinelli, E.; Paolesse, R.; D'Arcangelo, G.; Roscioni, C.; Finazzi-Agrò, A.; D’Amico, A. Lung cancer identification by the analysis of breath by means of an array of non-selective gas sensors. Biosens. Bioelectron. 2003, 18, 1209-1218. [CrossRef]

37. Westenbrink, E.; Arasaradnam, R.P.; O'Connell, N.; Bailey, C.; Nwokolo, C.; Bardhan, K.D.; Covington, J.A. Development and application of a new electronic nose instrument for the detection of colorectal cancer. Biosens. Bioelectron. 2015, 67, 733-738. [CrossRef]

38. D'Amico, A.; Pennazza, G.; Santonico, M.; Martinelli, E.; Roscioni, C.; Galluccio, G.; Paolesse, R.; Di Natale, C. An investigation on electronic nose diagnosis of lung cancer. Lung Cancer 2010, 68, 170-176. [CrossRef]

39. Machado, R.F.; Laskowski, D.; Deffenderfer, O.; Burch, T.; Zheng, S.; Mazzone, P.J.; Mekhail, T.; Jennings, C.; Stoller, J.K.; Pyle, J.; et al. Detection of Lung Cancer by Sensor Array Analyses of Exhaled Breath. Am. J. Respir. Crit. Care Med. 2005, 171, 1286-1291. [CrossRef] [PubMed]

40. Shlomi, D.; Abud, M.; Liran, O.; Bar, J.; Gai-Mor, N.; Ilouze, M.; Onn, A.; Ben-Nun, A.; Haick, H.; Peled, N. Detection of Lung Cancer and EGFR Mutation by Electronic Nose System. J. Thorac. Oncol. 2017, 12, 1544-1551. [CrossRef] [PubMed]

41. Saidi, T.; Moufid, M.; de Jesus Beleño-Saenz, K.; Welearegay, T.G.; El Bari, N.; Lisset Jaimes-Mogollon, A.; Ionescu, R.; Bourkadi, J.E.; Benamor, J.; El Ftouh, M.; et al. Non-invasive prediction of lung cancer histological types through exhaled breath analysis by UV-irradiated electronic nose and GC/QTOF/MS. Sens. Actuators B Chem. 2020, 311, 127932. [CrossRef]

42. De León-Martíne, D.L.; Rodríguez-Aguilar, M.; Gorocica-Rosete, P.; Domínguez-Reyes, C.A.; Martínez-Bustos, V.; Tenorio-Torres, J.A.; Ornelas-Rebolledo, O.; Cruz-Ramos, J.A.; Balderas-Segura, B.; Flores-Ramírez, R. Identification of profiles of volatile organic compounds in exhaled breath by means of an electronic nose as a proposal for a screening method for breast cancer: A case-control study. J. Breath Res. 2020, 14, 46009. [CrossRef] [PubMed]

43. De Meij, T.G.; Larbi, I.B.; van der Schee, M.P.; Lentferink, Y.E.; Paff, T.; Terhaar sive Droste, J.S.; Mulder, C.J.; van Bodegraven, A.A.; de Boer, N.K. Electronic nose can discriminate colorectal carcinoma and advanced adenomas by fecal volatile biomarker analysis: Proof of principle study. Int. J. Cancer 2014, 134, 1132-1138. [CrossRef]

44. Amal, H.; Leja, M.; Funka, K.; Lasina, I.; Skapars, R.; Sivins, A.; Ancans, G.; Kikuste, I.; Vanags, A.; Tolmanis, I.; et al. Breath testing as potential colorectal cancer screening tool. Int. J. Cancer 2016, 138, 229-236. [CrossRef]

45. Asimakopoulos, A.D.; Del Fabbro, D.; Miano, R.; Santonico, M.; Capuano, R.; Pennazza, G.; D’Amico, A.; Finazzi-Agrò, E. Prostate cancer diagnosis through electronic nose in the urine headspace setting: A pilot study. Prostate Cancer Prostatic Dis. 2014, 17, 206-211. [CrossRef] [PubMed]

46. Waltman, C.G.; Marcelissen, T.A.T.; van Roermund, J.G.H. Exhaled-breath Testing for Prostate Cancer Based on Volatile Organic Compound Profiling Using an Electronic Nose Device (Aeonose ${ }^{\mathrm{TM}}$ ): A Preliminary Report. Eur. Urol. Focus 2020, 6, 1220-1225. [CrossRef]

47. Bannaga, A.S.; Tyagi, H.; Daulton, E.; Covington, J.A.; Arasaradnam, R.P. Exploratory Study Using Urinary Volatile Organic Compounds for the Detection of Hepatocellular Carcinoma. Molecules 2021, 26, 2447. [CrossRef]

48. Chang, Y.; Li, W.; Yang, Z. Network Intrusion Detection Based on Random Forest and Support Vector Machine. In Proceedings of the 2017 IEEE International Conference on Computational Science and Engineering (CSE) and IEEE International Conference on Embedded and Ubiquitous Computing (EUC), Guangzhou, China, 21-24 July 2017; Volume 1, pp. $635-638$.

49. Butcher, J.B.; Rutter, A.V.; Wootton, A.J.; Day, C.R.; Sulé-Suso, J. Artificial Neural Network Analysis of Volatile Organic Compounds for the Detection of Lung Cancer. In Advances in Computational Intelligence Systems; Chao, F., Schockaert, S., Zhang, Q., Eds.; Springer International Publishing: Cham, Switzerland, 2018; pp. 183-190.

50. Esfahani, S.; Wicaksono, A.; Mozdiak, E.; Arasaradnam, R.P.; Covington, J.A. Non-Invasive Diagnosis of Diabetes by Volatile Organic Compounds in Urine Using FAIMS and Fox4000 Electronic Nose. Biosensors 2018, 8, 121. [CrossRef] [PubMed]

51. Da Costa, B.R.B.; De Martinis, B.S. Analysis of urinary VOCs using mass spectrometric methods to diagnose cancer: A review. Clin. Mass Spectrom. 2020, 18, 27-37. [CrossRef]

52. Hanai, Y.; Shimono, K.; Matsumura, K.; Vachani, A.; Albelda, S.; Yamazaki, K.; Beauchamp, G.K.; Oka, H. Urinary Volatile Compounds as Biomarkers for Lung Cancer. Biosci. Biotechnol. Biochem. 2012, 76, 679-684. [CrossRef]

53. Wishart, D.S.; Feunang, Y.D.; Marcu, A.; Guo, A.C.; Liang, K.; Vázquez-Fresno, R.; Sajed, T.; Johnson, D.; Li, C.; Karu, N.; et al. HMDB 4.0: The human metabolome database for 2018. Nucleic Acids Res. 2018, 46, D608-D617. [CrossRef] [PubMed]

54. Batty, C.A.; Cauchi, M.; Lourenço, C.; Hunter, J.O.; Turner, C. Use of the Analysis of the Volatile Faecal Metabolome in Screening for Colorectal Cancer. PLoS ONE 2015, 10, e0130301. [CrossRef] [PubMed]

55. Altomare, D.; Di Lena, M.; Porcelli, F.; Trizio, L.; Travaglio, E.; Tutino, M.; Dragonieri, S.; Memeo, V.; de Gennaro, G. Exhaled volatile organic compounds identify patients with colorectal cancer. Br. J. Surg. 2013, 100, 144-150. [CrossRef] 
56. De Vietro, N.; Aresta, A.; Rotelli, M.T.; Zambonin, C.; Lippolis, C.; Picciariello, A.; Altomare, D.F. Relationship between cancer tissue derived and exhaled volatile organic compound from colorectal cancer patients. Preliminary results. J. Pharm. Biomed. Anal. 2020, 180, 113055. [CrossRef]

57. Altomare, D.F.; Di Lena, M.; Porcelli, F.; Travaglio, E.; Longobardi, F.; Tutino, M.; Depalma, N.; Tedesco, G.; Sardaro, A.; Memeo, R.; et al. Effects of Curative Colorectal Cancer Surgery on Exhaled Volatile Organic Compounds and Potential Implications in Clinical Follow-up. Ann. Surg. 2015, 262, 862-867. [CrossRef]

58. Wang, G.; Li, Y.; Liu, M.; Guo, N.; Han, C.; Liu, D.; Li, D.; Yang, M.; Peng, Y.; Liu, Y.; et al. Determination of volatile organic compounds in SW620 colorectal cancer cells and tumor-bearing mice. J. Pharm. Biomed. Anal. 2019, 167, 30-37. [CrossRef]

59. Zonta, G.; Anania, G.; Fabbri, B.; Gaiardo, A.; Gherardi, S.; Giberti, A.; Guidi, V.; Landini, N.; Malagù, C. Detection of colorectal cancer biomarkers in the presence of interfering gases. Sens. Actuators B Chem. 2015, 218, 289-295. [CrossRef]

60. Liu, M.; Li, Y.; Wang, G.; Guo, N.; Liu, D.; Li, D.; Guo, L.; Zheng, X.; Yu, K.; Yu, K.; et al. Release of volatile organic compounds (VOCs) from colorectal cancer cell line LS174T. Anal. Biochem. 2019, 581, 113340. [CrossRef]

61. Silva, C.L.; Passos, M.; Câmara, J.S. Investigation of urinary volatile organic metabolites as potential cancer biomarkers by solid-phase microextraction in combination with gas chromatography-mass spectrometry. Br. J. Cancer 2011, 105, 1894-1904. [CrossRef]

62. Arasaradnam, R.P.; McFarlane, M.J.; Ryan-Fisher, C.; Westenbrink, E.; Hodges, P.; Thomas, M.G.; Chambers, S.; O'Connell, N.; Bailey, C.; Harmston, C.; et al. Detection of Colorectal Cancer (CRC) by Urinary Volatile Organic Compound Analysis. PLoS ONE 2014, 9, e108750. [CrossRef] [PubMed]

63. Wong, N.P.; Patton, S.; Forss, D.A. Methyl Ketones in Evaporated Milk1. J. Dairy Sci. 1958, 41, 1699-1705. [CrossRef]

64. Goldberg, E.M.; Blendis, L.M.; Sandler, S. A gas chromatographic-Mass spectrometric study of profiles of volatile metabolites in hepatic encephalopathy. J. Chromatogr. B Biomed. Sci. Appl. 1981, 226, 291-299. [CrossRef]

65. Bond, A.; Greenwood, R.; Lewis, S.; Corfe, B.; Sarkar, S.; O’Toole, P.; Rooney, P.; Burkitt, M.; Hold, G.; Probert, C. Volatile organic compounds emitted from faeces as a biomarker for colorectal cancer. Aliment. Pharmacol. Ther. 2019, 49, 1005-1012. [CrossRef] [PubMed]

66. Altomare, D.; Picciariello, A.; Rotelli, M.; Fazio, M.; Aresta, A.; Zambonin, C.; Vincenti, L.; Trerotoli, P.; De Vietro, N. Chemical signature of colorectal cancer: Case-control study for profiling the breath print. BJS Open 2020, 4, 1189-1199. [CrossRef] [PubMed] 